\title{
A tale of two pipes: Using whole rock geochemistry to see through alteration and contamination at the CH-6 \& CH-7 kimberlites, Chidliak kimberlite province, Baffin Island, Nunavut.
}

\author{
Pell $^{1}$, J., Grütter ${ }^{1}$, H.S., and Williams ${ }^{2}$, N. \\ 1. Peregrine Diamonds Ltd, Vancouver, BC, Canada,jennifer@pdiam.com \\ 2. High Power Exploration, Vancouver, BC, Canada.
}

\section{Introduction}

Major and trace element whole rock geochemistry is a simple and inexpensive tool that can be applied to monitor the similarities or differences between kimberlites. Here, we present major and trace element data for archetypal carbonate-serpentine-monticellite kimberlites from the Hall Peninsula on Baffin Island, Nunavut, Canada with a focus on the $\mathrm{CH}-6$ and $\mathrm{CH}-7$ pipes (181 and 428 samples respectively) on Peregrine Diamonds' $100 \%$ held Chidliak project. We also analyzed 44 samples of country rock gneisses and six samples of sedimentary carbonate xenoliths. The goals of this study were to see if whole rock geochemistry could be used to distinguish completely altered kimberlite from completely altered country rock and to differentiate kimberlite units/grade domains within a pipe, especially when the kimberlite had been weathered or altered.

The CH-6 kimberlite is infilled by two main geological units which are distinguished megascopically by the respective presence or paucity of Paleozoic carbonate xenoliths. KIM-L varies from pyroclastic kimberlite (PK) to apparently coherent kimberlite (ACK); when weathered it is denoted as wKIM-L. A high-grade zone (KIM-L-HG) has been defined based on microdiamond content. KIM-C is a comparatively homogeneous coherent kimberlite (CK). A minor unit, KIM-HK, occurs as carbonate xenolith-free CK horizons in KIM-L. Carbonate, serpentine \pm monticellite and, to a lesser extent, phlogopite are the dominant matrix minerals throughout $\mathrm{CH}-6$. Six main geological units have been recognized at CH-7, each with distinct physical characteristics. KIM-1 is coarse-grained CK, KIM-6 is a gneiss xenolith-bearing CK, whereas KIM-2, KIM-3 and KIM-4 are PK. KIM-5 is texturally variable (PK, ACK) and locally lateritized; it also has a high-grade sub-unit (KIM-5-(H)). KIM-2 and KIM-6 have a serpentine-dominated groundmass/matrix, KIM-3 is carbonate-dominated, KIM-1 contains monticellite-carbonate-serpentine and the other units have a carbonate \pm serpentine matrix. Phlogopite is present locally, but not as prevalent as in CH-6. In both pipes, crustal dilution is 5 volume \% or less on average and the upper $40-50 \mathrm{~m}$ are very weathered. Also, in both pipes, a number of samples cannot be readily assigned to a lithologic unit using conventional logging and petrology, due to weathering and alteration among other things and are currently classified as "RFW" (requires further work.).

\section{Data Analysis and Interpretation}

Initial analysis of the data began eliminating elements from the dataset where most of the results were below detection limit and then testing the remaining elements for mobility: $\mathrm{Ca}, \mathrm{K}, \mathrm{Rb}, \mathrm{Sr}, \mathrm{Ba}$ and $\mathrm{Na}$ are mobile and depleted during near-surface alteration/weathering; incompatible, high field strength elements (Nb-Ta, U-Th, Zr-Hf, REEs-Y) as well as Ti, Al, Ga, Cu, Cr, Fe, Mn, P and V are immobile and conserved. Simple bivariate plots of conserved elements have little value for discrimination of kimberites at Chidliak, despite their discriminatory attributes noted for the Attawapiskat kimberlites (Fig. 1). Ratio-ratio plots that utilized incompatible, immobile elements were used in an attempt to differentiate the known geological units and readily showed distinctly different, albeit overlapping, compositional attributes for the different kimberlite units that were logged at $\mathrm{CH}-7$. The same approach failed to clearly and unambiguously describe geological units or known grade domains at CH-6; instead they showed remarkably similar compositions throughout CH-6 (Fig. 2). However, simple plots such as $\mathrm{Al} / \mathrm{Ti}$ vs $\mathrm{Nb} / \mathrm{Ga}$ or Ti/Ga vs Nb/Ga proved to be extremely useful in discriminating completely clayaltered and unrecognizable kimberlite from similarly unrecognizable country rocks (not illustrated). 

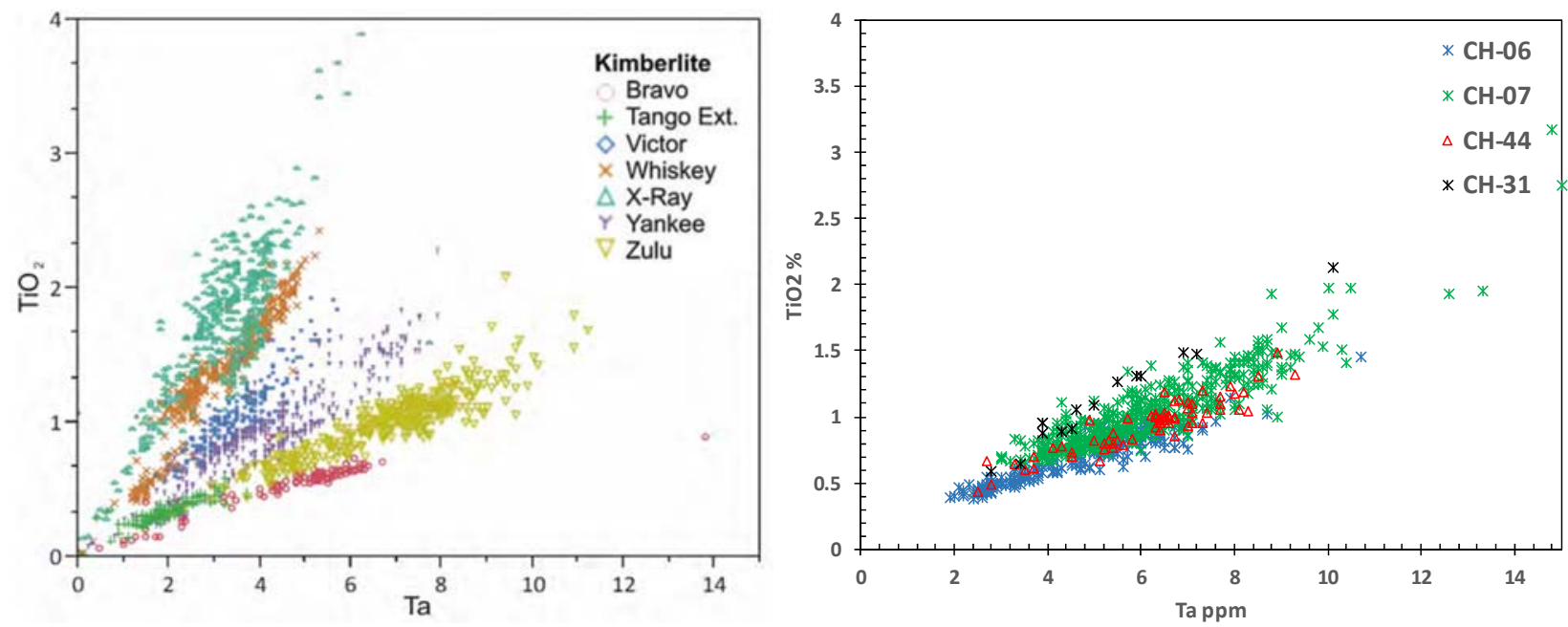

Figure 1: Simple bivariate element plots show clear differences between Attawapiskat kimberlites (plot on left, from Januszczak et al., 2013), but have proved ineffective to distinguish between kimberlites at Chidliak (plot on right).
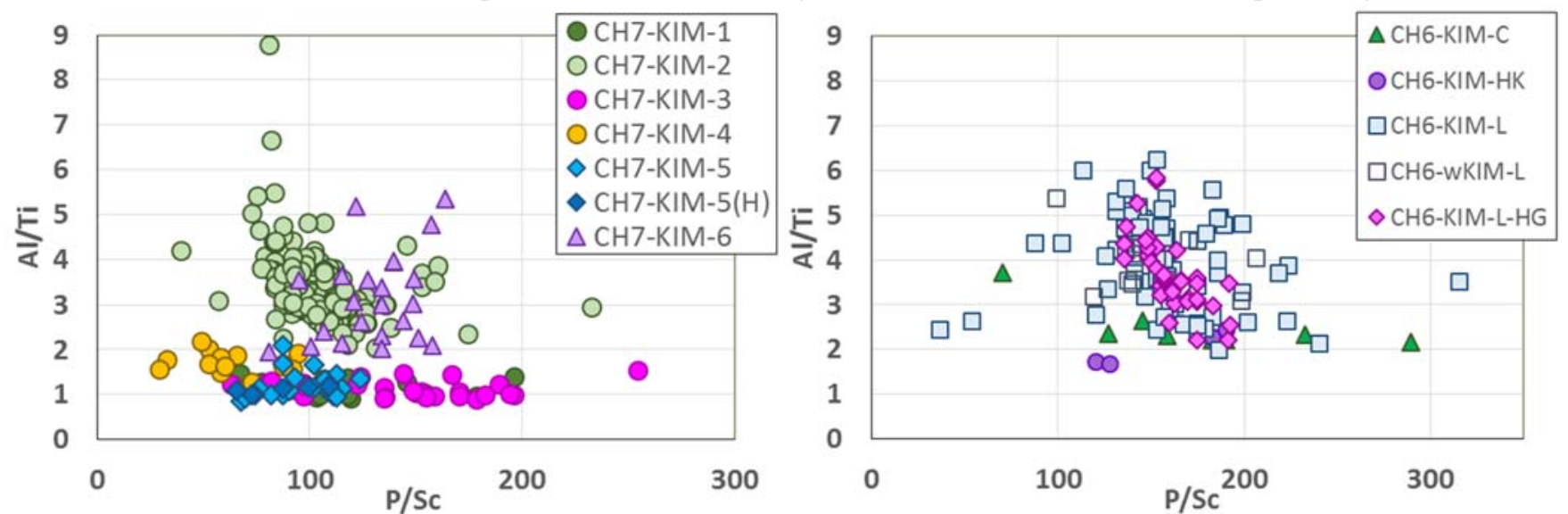

Figure 2: Element ratio-ratio plots for $\mathrm{CH}-7$ (left) and $\mathrm{CH}-6$ (right). At $\mathrm{CH}-7$ there is some differentiation between units, particularly separating the serpentine-dominated (KIM-2 and KIM-6) from the low Al/Ti carbonate-rich units. The low $\mathrm{Al} / \mathrm{Ti}$ lithologies do not occur at $\mathrm{CH}-6$.

Multivariate techniques were employed to take the study to the next level. Principal component analysis (PCA) was remarkably efficient at identifing those elements that best define primary kimberlite magma compositions, and identify element associations related to mantle and crustal contamination. Outcomes of this part of the study were: 1) Si, Mg, Fe, Ni, Co \& Zn show similar behaviour, interpreted to reflect olivine abundance and so tracks mantle contamination; 2) $\mathrm{Al}$ and $\mathrm{Ga}$ reflect the groundmass serpentine content (see Fig. 2) and, at CH-6, K-Rb \& Sr are related to the abundance of matrix/groundmass phlogopite rather than being controlled by country rock gneisses contamination; and 3) the primary magma compositions are best described at both localites by Ti, Nb-Ta, Cr, REEs-Y, U-Th, \& Sc. Additionally $\mathrm{Mn}, \mathrm{Ba} \& \mathrm{~K}-\mathrm{Rb}-\mathrm{Sr}$ at $\mathrm{CH}-6$ and $\mathrm{Cu}, \mathrm{V}, \mathrm{P} \& \mathrm{Zr}$ at $\mathrm{CH}-7$ relate to primary magma compositions.

A number of unsupervised and supervised classification techniques available in MATLAB ${ }^{\circledR}$ were applied to (i) the limited element suite that describes the CH-7 primary kimberlite magma, and (ii) to a wider suite of 39 elements (though excluding LOI, Total C and elements mobiled during weathering). The best results were obtained when a mulitvariate analysis of variance (MANOVA) was applied to generate a linear discriminant analysis (LDA) to find the canonical variables that best isolate units from the 39-element log-centred ratio transformed (LCRT) data, with the transformed data classified using a linear discriminant supervised classifier. In this case, self-recognition accuracy of $97 \%$ was obtained (Fig. 3). The self-recognition accuracy is $94.8 \%$ when these routines are applied to the more limited 
primary magma element suite for $\mathrm{CH}-7$. The self-recognition results inspire confidence in using these techniques to help classify the "RFW" samples from CH-7.

At CH-6, we went directly to the last step, MANOVA on LCRT data (42 elements, retaining Ba-K-Rb-Sr, the phlogopite component, which had not been used at $\mathrm{CH}-$ 7 because they were mobile, and eliminating $\mathrm{Pb}$ ) and then ran the supervised classifiers. The results for $\mathrm{CH}-6$ were not as satisfactory, for the LDA classifier, with only $76.8 \%$ self-recognition of units on the full element suite and $75.4 \%$ on the primary magma element suite. However, a RUSBoosted Trees supervised classifier returned $88.4 \%$ self recognition of units on the full element suite. At $\mathrm{CH}-6$, the number of samples in each unit is strongly biased (89 in KIM-L, 8 in KIM-C); the RUSBoosted Tree classifier returned the best results since it compensates for unbalanced class sizes by undersampling the over-represented classes. The best results for the primary magma element suite $(77.5 \%)$ were obtained using a Simple Tree classifier, which is not adequate to allow confident classification of the $\mathrm{CH}-6$ "RFW" samples.

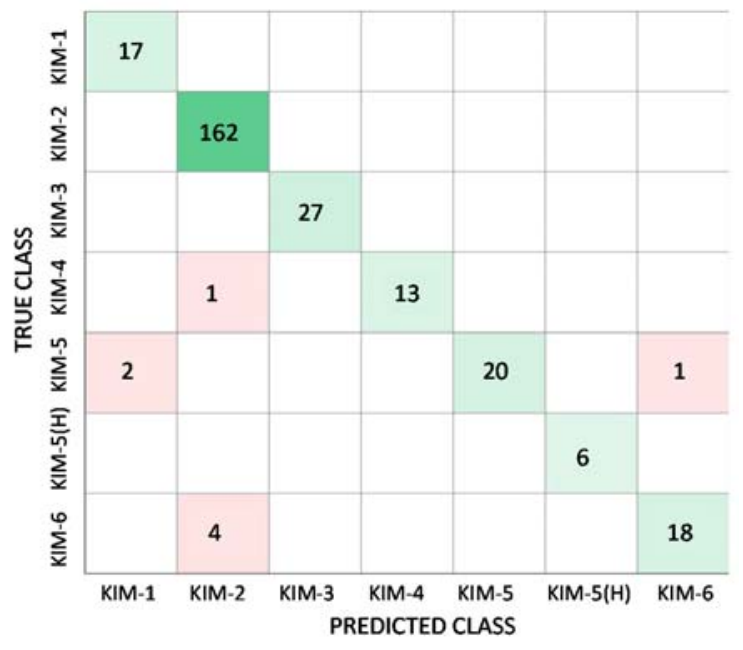

Figure 3: Confusion matrix for the LDA geochemical classification of $\mathrm{CH}-7$ kimberlite. Numbers in the boxes are numbers of samples in each class.

\section{Discussion}

Multivariate analyses, particularly linear discriminant analyses, of whole rock geochemical datasets predominantly using the immobile elements, has proven in this, and other studies (e.g. Grunsky and Kjarsgaard, 2008) to be a useful tool in differenting kimberlite units where clear differences exist. It therefore can be used to help classify weathered and altered rocks particulary when subjective techniques such as petrography are not capable of doing so. However, these techniques were not as successful in differentiating units where differences are subtle and undersampling of some units is an issue. It is likely that better results would be obtained from data sets where all units had roughly equal numbers of samples.

For the CH-6 and CH-7 kimberlites at Chidliak, significant geochemical variability was found to be dominated by the crustal or mantle contaminants, and geochemical variability was only subtly related to kimberlite magmas sensu stricto (e.g. Nb, LREEs). The best unit discrimination was obtained when all elements, except those most mobile during weathering, were considered, essentially treating the kimberlite as the sum of its complete history and composition, not simply considering its magmatic component.

\section{References}

Grunsky, E.C. and Kjarsgaard, B.A., 2008. Classification of distinct eruptive phases of the diamondiferous Star kimberlite, Saskatchewan, Canada baed on statistical treatment of whole rock geochemical data. Applied Geochemistry 23, 3321-3336.

Januszczak, N., Seller, M.H., Kurszlaukis, S., Murphy, C., Delgaty, J., Tappe, S., Ali, K., Zhu, J. and Ellmers, P., 2013. A multidisciplinary approach to the Attawapiskat Kimberlite Field, Canada: Accelerating the discovery-to-production pipeline. In D.G. Pearson et al. (eds), Proceedings of $10^{\text {th }}$ Intenational Kimberlite Conference, V2, Special Issue of the Journal of the Geological Society of India, 157-171. 